\title{
Astrocytes in the Rat Nucleus Tractus Solitarii Are Critical for Cardiovascular Reflex Control
}

\author{
Li-Hsien Lin, ${ }^{1}$ Steven A. Moore, ${ }^{2}$ Susan Y. Jones, ${ }^{1}$ Jacob McGlashon, ${ }^{1}$ and William T. Talman ${ }^{1}$ \\ ${ }^{1}$ Laboratory of Neurobiology, Department of Neurology, Carver College of Medicine, The University of Iowa and Iowa City Veterans Affairs Medical Center, \\ Iowa City, Iowa 52242, and 2Department of Pathology, Caver College of Medicine, The University of Iowa, Iowa City, Iowa 52242
}

We have shown that an antibody to dopamine- $\beta$-hydroxylase conjugated with saporin (anti-DBH-SAP) damages catecholamine neurons in the nucleus tractus solitarii (NTS) of rat, attenuates arterial baroreflexes, and leads to lability of arterial blood pressure, damage to cardiac myocytes, and, in some animals, sudden death. However, others have shown that injection of 6-hydroxydopamine (6-0HDA), a toxin devoid of saporin, also damaged NTS catecholamine neurons but did not lead to these cardiovascular changes. We found similar cardiovascular changes after injecting a different SAP conjugate to target NTS neurons with neurokinin (NK1) receptors. Because ribosome-inactivating proteins may be toxic to glia, we hypothesized that SAP, a ribosome-inactivating protein, might target glia whose loss could account for physiological changes. We tested this hypothesis by assessing effects on select neurons and on glia in the NTS after exposure to SAP, targeted SAP conjugates, or 6-OHDA. SAP and all SAP conjugates led to loss of immunoreactivity for glial fibrillary acidic protein, a marker for astrocytes, in the NTS while 6-OHDA did not. As reported previously, anti-DBH-SAP selectively killed noradrenergic neurons in the NTS while SAP conjugated to stabilized substance P (SSP-SAP) selectively killed neurons with NK1 receptors. In contrast, SAP produced no demonstrable neuronal damage. All injections led to activation of microglia in the NTS; however, only SAP and its conjugates attenuated cardiovascular reflexes while also producing lability of arterial pressure, damage to cardiac myocytes, and in some animals, sudden death. Thus, NTS astrocytes may play a role in mediating cardiovascular reflex transmission through the NTS.

\section{Introduction}

We have previously reported that injection into the nucleus tractus solitarii (NTS) of saporin (SAP) conjugated with substance P (SP-SAP) or stabilized SP (SSP-SAP) eliminated neurons expressing the neurokinin receptor 1 (NK1R) in the NTS and also attenuated arterial baroreflex responses (Riley et al., 2002; Nayate et al., 2009). The relative selectivity of SAP conjugates for specific neuronal types has been shown by others (Wiley and Lappi, 1997, 1999; Madden et al., 1999) and was supported by our finding that treatment with SSP-SAP did not lead to loss of neurons with the biosynthetic enzyme, tyrosine hydroxylase $(\mathrm{TH})$, which is essential for norepinephrine synthesis (Lin et al., 2012b). In contrast, injection into the NTS of anti-dopamine $\beta$-hydroxylase-SAP (anti-DBH-SAP), which led to a significant loss of TH and DBH neurons, while not affecting NTS neurons with the NK1R, also attenuated the arterial baroreflex and caused significant lability of arterial pressure (Talman et al., 2012). Our findings would be consistent with an integral role for both types of neuron in trans-

\footnotetext{
Received July 31, 2013; revised Sept. 30, 2013; accepted 0ct. 21, 2013.

Author contributions: L.-H.L. and W.T.T. designed research; L.-H.L., S.M., S.Y.J., and J.M. performed research;

L.-H.L., S.M., S.Y.J., and W.T.T. analyzed data; L.-H.L., S.M., S.Y.J., J.M., and W.T.T. wrote the paper.

The authors gratefully acknowledge support provided by NIH R01 HL088090 (W.T.T. and L.-H.L., PIs) and by VA Merit Review (W.T.T. PI).

The authors declare no competing financial interests.

Correspondence should be addressed to Dr. William T. Talman, Department of Neurology, Carver College of Medicine, University of lowa, lowa City, IA 52242. E-mail: william-talman@uiowa.edu.

DOI:10.1523/JNEUROSCI.3257-13.2013

Copyright $\odot 2013$ the authors $\quad 0270-6474 / 13 / 3318608-10 \$ 15.00 / 0$
}

mission or modulation of baroreflexes as has been suggested by others (Snyder et al., 1978; Gillis et al., 1980; Helke et al., 1980). However, our analysis of neuronal types affected by SSP-SAP showed that the toxin not only rid the NTS of neurons with the NK1R but also killed NTS neurons that expressed NMDA and AMPA receptors (Lin et al., 2012b), a finding consistent with our observation (Lin et al., 2008) that these glutamate receptor types colocalize with NK1R. Thus, their loss would be expected if neurons with the latter receptor were targeted by the toxin. Furthermore, though treatment with anti-DBH-SAP reduced neuronal staining for catecholamine neurons, others (Itoh et al., 1992) had shown different cardiovascular effects when catecholamine neurons in NTS were exposed to another targeted toxin, 6-hydroxydopamine (6-OHDA). That study reported decreased, not increased, lability of arterial pressure and a variable effect on baroreflex function. Because it has been shown that glial cells are very sensitive to type 2 ribosome-inactivating proteins, such as ricin and volkensin (Sparapani et al., 1997), these conflicting reports raised the possibility that anti-DBH-SAP could be affecting non-neuronal elements in the NTS. We conjectured that SAP, the active toxin in anti-DBH-SAP, could be cytotoxic to glia despite it being a type 1 ribosome-inactivating protein that putatively cannot enter cells unless complexed to a membrane-binding carrier (Ippoliti et al., 2000; Wiley and Kline, 2000). We sought to determine whether glia were indeed susceptible to SAP toxicity and to test the hypothesis that unconjugated SAP could target glia in the absence of demonstrable toxic effects on neurons. To test the hypothesis we performed physiological studies that included ra- 
Table 1. Sources and dilutions of primary antibodies used for fluorescent immunostaining

\begin{tabular}{lllll}
\hline Antibody & Immunogen & Host & Source & Dilution \\
\hline TH & Denatured rat TH & Rabbit & Millipore AB152 & $1: 200$ \\
DBH & Purified bovine DBH & Mouse & Millipore MAB308 & $1: 500$ \\
NMDAR1 $^{a}$ & NMDAR1 aa 0.660-811 & Mouse & Millipore MAB363 & $1: 100$ \\
& Human NMDA 51 & Goat & Santa Cruz Biotechnology SC-1467 & $1: 25$ \\
PGP9.5 $^{a}$ & Purified human PGP9.5 & Rabbit & Millipore AB1761ASR & $1: 100$ \\
& Human PGP9.5 aa 175-191 Guinea & Millipore AB5898 & $1: 50$ \\
& & pig & & \\
NK1R & Synthetic rat NK1R peptide & Rabbit & Novus Biological NB300-101 & $1: 50$ \\
GFAP & Human GFAP peptide & Goat & Santa Cruz Biotechnology SC-6170 & $1: 50$ \\
& Purified pig GFAP & Mouse & Sigma-Aldrich G3893 & $1: 200$ \\
CX43 & Human CX43 aa 233-382 & Rabbit & Santa Cruz Biotechnology SC-9059 & $1: 25$ \\
OX42 & Rat 0X42 (CD11b) & Mouse & AbD Serotec MCA275R & $1: 100$ \\
\hline
\end{tabular}

NMDAR1, NMDA receptor subunit type 1.

${ }^{a}$ We observed similar patterns of staining in the NTS for the two different sources of antibodies listed.

diotelemetry monitoring of arterial blood pressure (AP), heart rate (HR), electrocardiogram (ECG), as well as baroreflex, chemoreflex, and von Bezold-Jarisch reflex testing after injection of toxins into the NTS. Efficacy and selectivity of toxins was assessed by immunofluorescent staining of neuronal and glial markers with confocal microscopic examination of stained sections of the NTS.

\section{Materials and Methods}

Humane use of animals. All procedures conformed to standards established in the Guide for Care and Use of Laboratory Animals. The Institutional Animal Care and Use Committees of the University of Iowa and Department of Veterans Affairs Medical Center, Iowa City, IA, reviewed and approved all protocols. Both institutions are AAALAC accredited. All efforts were made to minimize the number of animals used and to avoid their experiencing pain or distress.

Microinjection. Adult ( $\sim 250-300 \mathrm{~g})$ male Sprague Dawley rats (Harlan Laboratories) were used in all studies. Microinjections were made into the NTS by previously described techniques (Nayate et al., 2009). Briefly, animals were anesthetized with isoflurane (5\% induction and $1.5-2 \%$ maintenance). The dorsal surface of the medulla oblongata over the dorsal vagal complex was exposed through a midline dorsal cervical incision and partial occipital craniotomy. Glass micropipettes containing desired injectates were stereotactically placed into the NTS at predetermined coordinates $(0.5 \mathrm{~mm}$ rostral to the calamus scriptorius, $0.5 \mathrm{~mm}$ to either side of the midline, and $0.5 \mathrm{~mm}$ beneath the dorsal surface of the brainstem at that site). All compounds were prepared in PBS and were injected bilaterally into the NTS. Injectates included PBS, SSP-SAP (3 ng in $100 \mathrm{nl}$ ), blank-SAP (3 $\mathrm{ng}$ in $100 \mathrm{nl}$ ), anti-DBH-SAP (42 $\mathrm{ng}$ in $200 \mathrm{nl}$ ), SAP ( $3 \mathrm{ng}$ in $100 \mathrm{nl}$ ), and 6-OHDA ( $1 \mu \mathrm{g}$ in $400 \mathrm{nl}$ ). (Note that blank-SAP is SAP conjugated to 11 aa in random sequence that bears no homology to any known protein. It was used as control for nonspecific effects of SAP conjugates. Further note that the concentration of SAP in each conjugate was as follows: SSP-SAP $=2.7 \mathrm{ng} / 100 \mathrm{nl}$; anti-DBH-SAP $=3$ $\mathrm{ng} / 100 \mathrm{nl}$; and blank SAP $=2.8 \mathrm{ng} / 100 \mathrm{nl}$.) In addition, SAP (3 ng in 100 $\mathrm{nl}$ ) was injected into the area postrema as a control site that lay adjacent to, but outside, the NTS. The number of animals used in each group and for each protocol is provided within each protocol in Results. Microinjections were made over $15 \mathrm{~min}$ in $25-50 \mathrm{nl}$ increments until the total volume was injected. Doses and volumes of each agent were chosen according to previous publications (Itoh and Buñag, 1993; Madden et al., 1999; Nattie et al., 2004; Tsutsui et al., 2011; Wilkinson et al., 2011; Talman et al., 2012) and were confirmed in preliminary experiments to produce significant immunofluorescent changes for the targeted cell types over homologous regions of NTS. The pipette was left in the brainstem for an additional $15 \mathrm{~min}$ to reduce efflux of fluid from the pipette track. SSP-SAP, SAP, blank-SAP, and anti-DBH-SAP were purchased from Advanced Targeting Systems. 6-OHDA was purchased from Sigma-Aldrich. For immunofluorescent studies to analyze toxic effects in
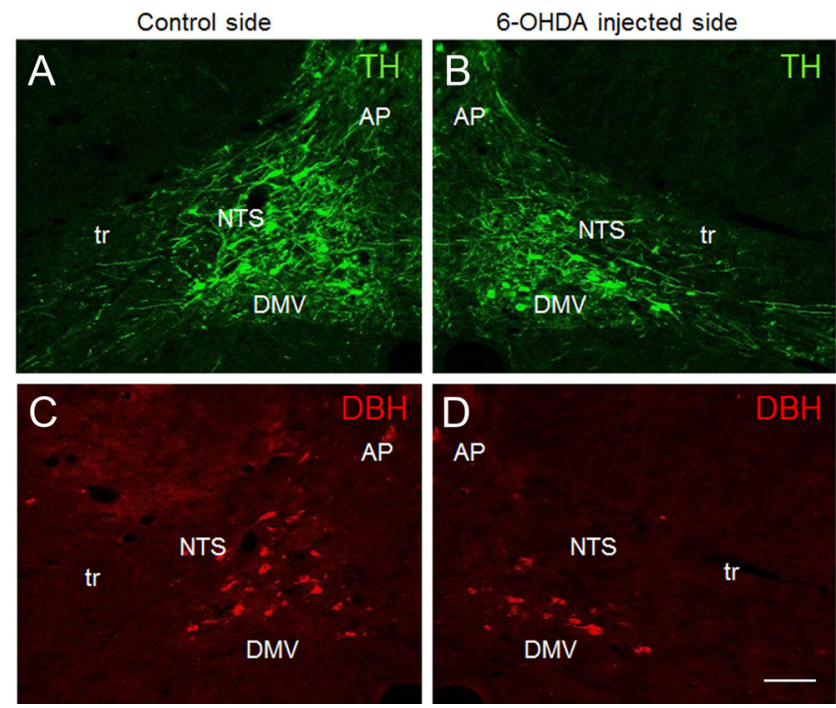

Figure 1. Confocal images of double immunofluorescent staining showing decreases in TH-IR $(\boldsymbol{B})$ and DBH-IR $(\boldsymbol{D})$ in the NTS after injection of 6-OHDA into this area when compared with those of the control side ( $\boldsymbol{A}, \boldsymbol{C}$, respectively) in the same section. AP, Area postrema; DMV, dorsal motor nucleus of vagus; tr, tractus solitarius. Scale bar, $100 \mu \mathrm{m}$.

Table 2. Changes in immunofluorescent markers of neurons and glia in NTS after local injection of toxin when compared with the uninjected side

\begin{tabular}{lcccccccc}
\hline & PGP9.5 & NMDAR1 & DBH & TH & NK1R & GFAP & CX43 & 0X42 \\
\hline SSP-SAP & $\downarrow$ & $\downarrow$ & $\uparrow$ & $\uparrow$ & $\downarrow$ & $\downarrow$ & $\downarrow$ & $\uparrow$ \\
Anti-DBH-SAP & - & - & $\downarrow$ & $\downarrow$ & - & $\downarrow$ & $\downarrow$ & $\uparrow$ \\
SAP & - & - & - & - & - & $\downarrow$ & $\downarrow$ & $\uparrow$ \\
Blank-SAP & - & - & - & - & - & $\downarrow$ & $\downarrow$ & $\uparrow$ \\
6-OHDA & - & - & $\downarrow$ & $\downarrow$ & - & - & - & $\uparrow$ \\
\hline
\end{tabular}

${ }^{a}$ Qualitative changes shown for SSP-SAP have been previously published (Lin et al., 2008, 2012b; Riley et al., 2002).

$\downarrow$ : Significant decrease $(p<0.05$ or less).

$\uparrow:$ Significant increase ( $p<0.05$ or less).

—: No significant change.

neuronal and glial markers in the NTS, injections were made unilaterally $(N=4-5$ for each type of toxin) with the noninjected side of NTS serving as a control in the same animal.

Instrumentation. Rats were anesthetized with isoflurane (5\%) delivered in $100 \%$ oxygen through a nasal cone. Anesthesia was maintained with inhaled isoflurane (1.5-2\%) throughout all experiments except during cardiovascular reflex testing (see below). Under isoflurane general anesthesia, some animals were instrumented as previously described (Nayate et al., 2009) for radiotelemetry monitoring of arterial blood pressure (AP), heart rate (HR), electrocardiogram (ECG), and temperature by means of a Data Sciences International (DSI) radiotelemetry transducer (Model C50-PXT) implanted through a midline abdominal incision with ECG electrodes implanted on the chest wall and a cannula inserted into the abdominal aorta via a femoral artery for recording AP and HR. After full preparation of the animal for each experiment (see further steps below) animals were treated with buprenorphine $(0.01 \mathrm{mg} /$ $\mathrm{kg}$ ) to achieve analgesia and were returned to their home cage, which was placed atop a DSI receiver plate that detected signals at $500 \mathrm{~Hz}$ for $10 \mathrm{~s}$ of every minute from the implanted device and transmitted those signals to an online computer where incoming data were recorded and stored.

Cardiovascular reflex analysis. Baroreflex activity was assessed by either sequence analysis (Bertinieri et al., 1985; Stauss et al., 2006) or by recording reflex tachycardic or bradycardic responses to pharmacologically induced decreases or increases in AP.

Sequence analysis was done as previously described (Talman et al., 2012) in awake, freely moving animals that were not disturbed by the examiner throughout each period of recording and was applied to the 


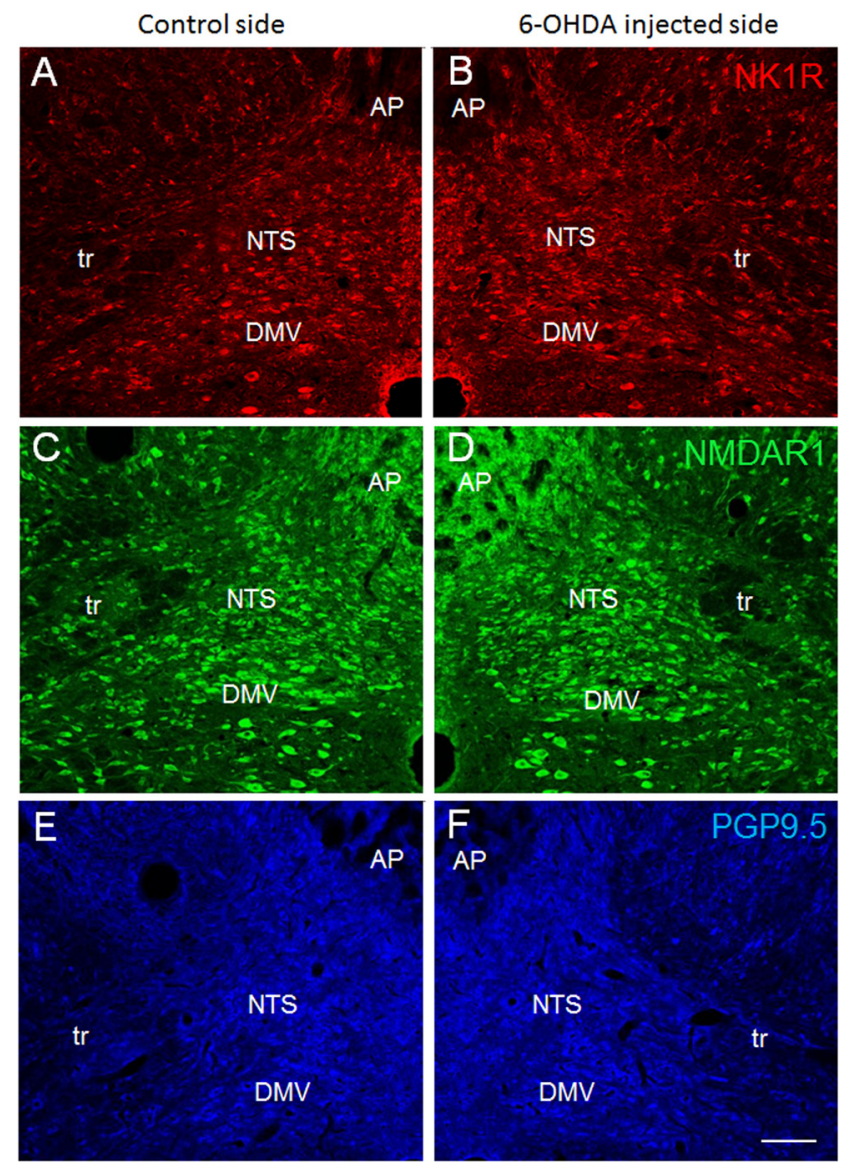

Figure 2. Confocal images of immunofluorescent staining showing no appreciable change in NK1-IR $(\boldsymbol{B})$, NMDAR1 (D), and PGP9.5 $(\boldsymbol{F})$ in the NTS after microinjection of 6-OHDA into this area when compared with that of the control side $(\boldsymbol{A}, \boldsymbol{C}, \boldsymbol{E}$, respectively). Likewise, no changes in these stainings were seen after injection of anti-DBH-SAP, SAP, or blank-SAP into the NTS. Abbreviations are as in Figure 1. Scale bar, $100 \mu \mathrm{m}$.

recordings obtained during the night time (6:00 P.M. to 6:00A.M.) of the last $24 \mathrm{~h}$ of the experimental protocol ( $7 \mathrm{~d}$ after toxin injection).

In separate animals we tested the arterial baroreflex, chemoreflex, or von Bezold-Jarisch reflex (see below) in animals anesthetized with chloralose $(45 \mathrm{mg} / \mathrm{kg}$ loading dose followed by $10 \mathrm{mg} / \mathrm{kg} / \mathrm{h}$ maintenance dose) as we have previously reported (Riley et al., 2002). Baroreflexinduced changes in HR were assessed after administration of phenylephrine $(1-25 \mu \mathrm{g} / \mathrm{kg})$ or sodium nitroprusside $(1-50 \mu \mathrm{g} / \mathrm{kg})$ delivered in random order $7 \mathrm{~d}$ after injection of toxin. $\mathrm{AP}(\mathrm{mmHg})$ and $\mathrm{HR}(\mathrm{bpm})$ were allowed to return to baseline between doses of each agent and before administration of the next dose. Although others (Head and McCarty, 1987) promoted sigmoid curve fitting to analyze a full range of changes in blood pressure $(60-160 \mathrm{mmHg})$ and $\mathrm{HR}$, we intentionally avoided such a full range to lessen activation of nonbaroreflex responses (Minisi et al., 1989 ) in this phase of the study. Not reaching a high or low asymptote in each animal precluded sigmoid curve-fitting analysis. Instead, as we have previously reported (Lin et al., 2012a), we applied linear regression to each limb of the reflex separately with all data forced through 0 .

In the same animals, chemoreflex testing was achieved by IV administration of $\mathrm{NaCN}(40 \mu \mathrm{g} / \mathrm{kg}) 7 \mathrm{~d}$ after toxin injection, and the von Bezold-Jarisch cardiopulmonary reflex was tested by IV administration of phenylbiguanide $(15 \mu \mathrm{g} / \mathrm{kg})$. Anesthesia was maintained with chloralose with animals breathing $100 \% \mathrm{O}_{2}$ through a nose cone, but during chemoreflex testing animals breathed room air to avoid blunting chemoreflex responses as a result of elevated arterial $\mathrm{pO}_{2}$ (Matsumoto et al., 1987; Sévoz et al., 1997).

Lability of AP was quantified as the SD of mean arterial pressure (MAP) (Nathan and Reis, 1977) recorded by radiotelemetry monitoring
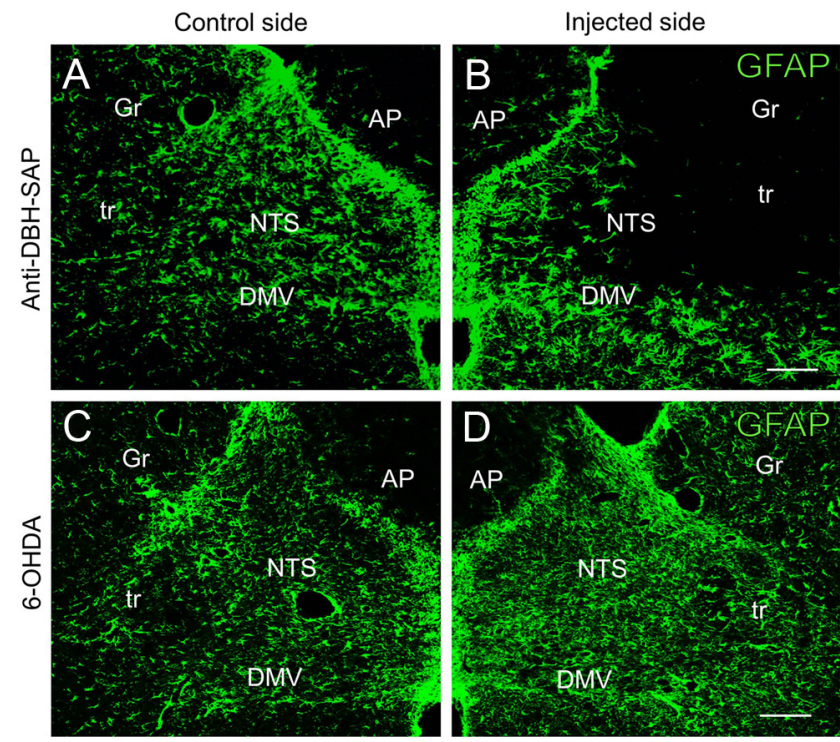

Figure 3. There is a dramatic decrease in GFAP-IR in the NTS after injection of anti-DBH-SAP into this area $(\boldsymbol{B})$ when compared with that of the control side $(\boldsymbol{A})$ in the same section. Similar decrease in GFAP-IR was observed after injection of SSP-SAP, SAP, and blank-SAP (data not shown) into the NTS. With each SAP-containing compound, as shown here, loss of GFAP was seen in the adjacent gracilis nucleus, which was also affected by the injection. In contrast to effects of anti-DBH-SAP, a slight increase in GFAP-IR was observed after 6-OHDA injection (D) when compared with the control side $(\boldsymbol{C})$ in the same section. Abbreviations are the same as in Figure 1 with addition of $\mathrm{Gr}$, nucleus gracilis. Scale bar, $100 \mu \mathrm{m}$.
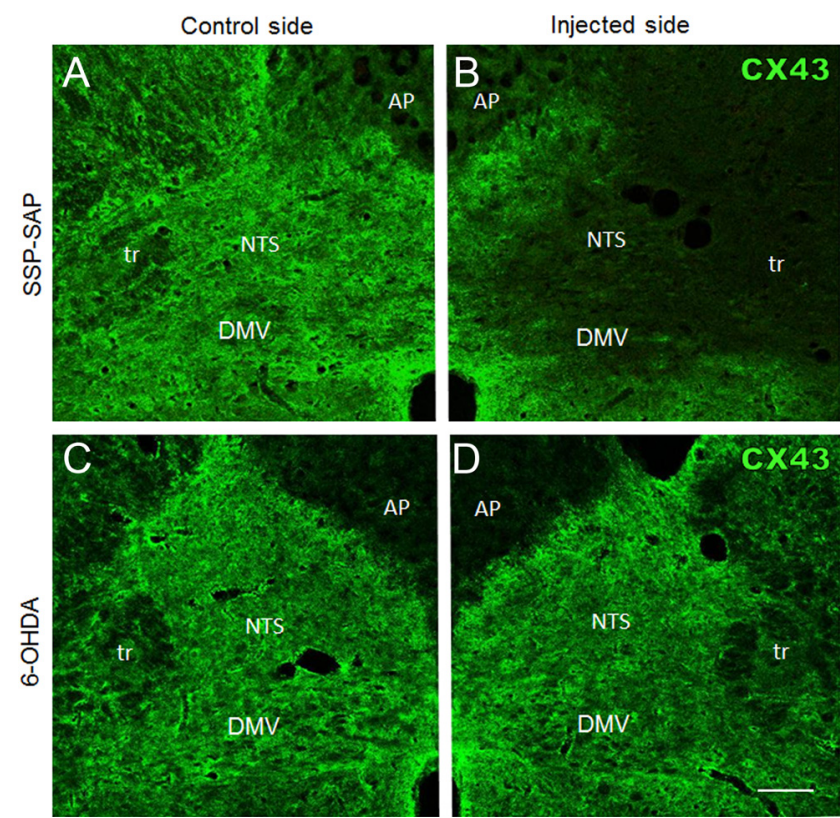

Figure 4. There is a dramatic decrease in $X X 43-I R$ in the NTS after injection of SSP-SAP into this area $(\boldsymbol{B})$ when compared with that of the control side $(\boldsymbol{A})$ in the same section. We observed similar dramatic decreases in CX43-IR after anti-DBH-SAP, SAP, or blank-SAP had been injected into the NTS. In contrast, only a slight reduction in CX43-IR in the NTS was noted after 6-OHDA injection (D) when compared with that of the control side $(\boldsymbol{C}$. Abbreviations are the same as in Figure 1. Scale bar, $100 \mu \mathrm{m}$.

in conscious, freely moving animals. All data were expressed as \pm SEM, and the control and experimental group results were subjected to independent ANOVA with Tukey's post hoc comparison and with significance accepted at a $p \leq 0.05$.

Pathological examination of the heart. After completion of all physiological testing, animals were killed with an overdose $(150 \mathrm{mg} / \mathrm{kg})$ of 

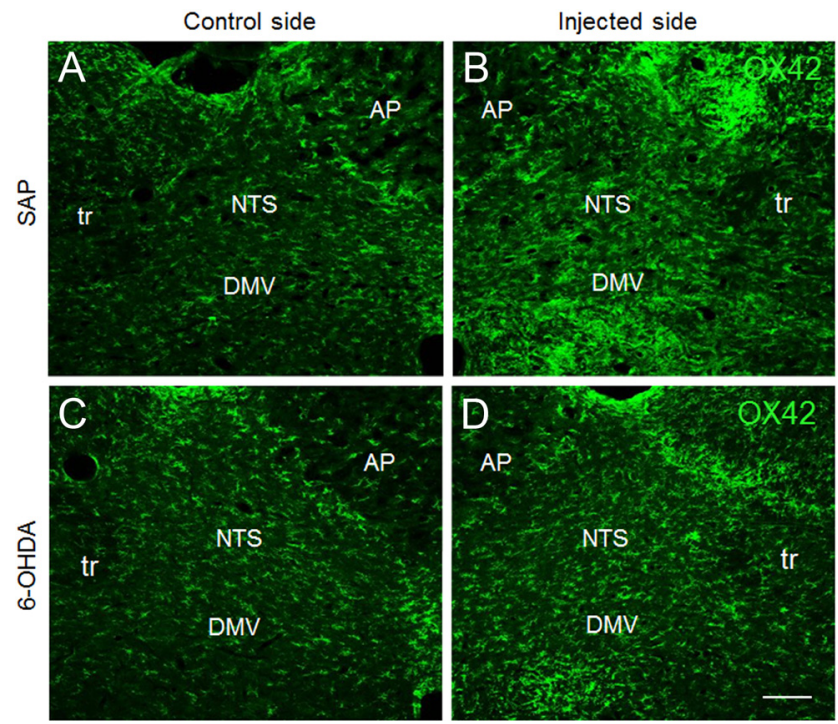

Figure 5. There was an increase in OX42-IR after SAP has been injected into the NTS $(\boldsymbol{B})$, when compared with that of the control side $(\boldsymbol{A})$. Similar increase in $0 X 42-1 \mathrm{R}$ was seen after the injection 6-OHDA in the NTS (D) when compared with the control side (C). Increase in OX42-IR was also seen after injection of SSP-SAP, blank-SAP, and anti-DBH-SAP. Abbreviations are as in Figure 1. Scale bar, $100 \mu \mathrm{m}$.

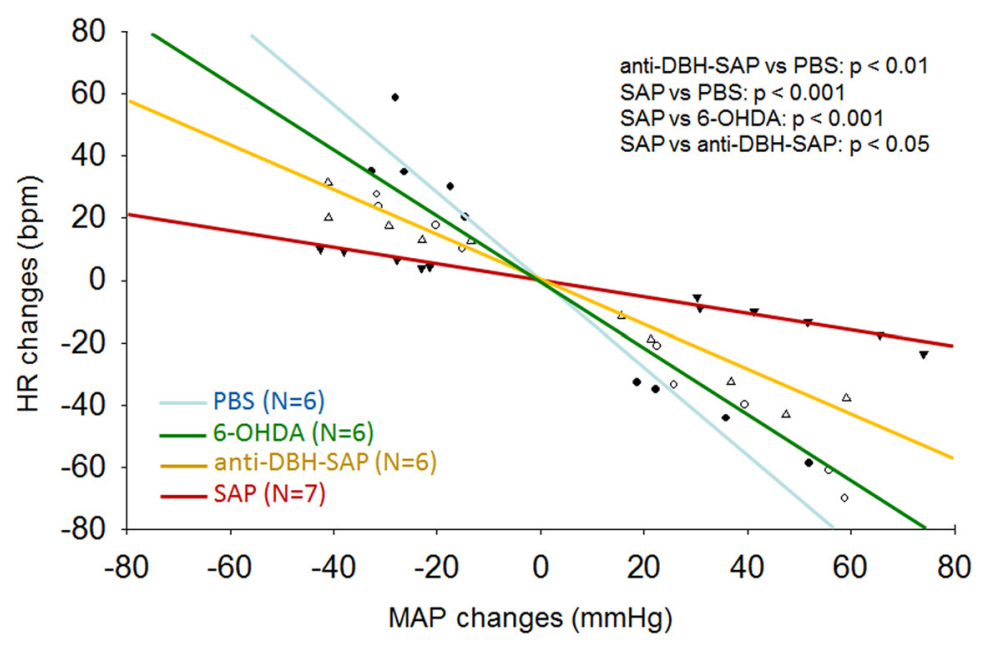

Figure 6. Baroreflex $7 \mathrm{~d}$ after injection of PBS, 6-OHDA, SAP, and 6-OHDA. Regression lines to the left of 0 show reflex increases in HR (ordinate) in response to decreases in MAP (abscissa) elicited by IV nitroprusside. Regression lines to the right of 0 show reflex decreases in HR in response to increases in MAP elicited by IV phenylephrine. Reflex responses were significantly $(p<0.05)$ attenuated in animals treated with anti-DBH-SAP when compared with those seen in animals treated with PBS and significantly attenuated in animals treated with SAP when compared with all other groups. There were no other significant differences between groups.

pentobarbital and the hearts were removed for pathological examination. To examine pathological changes in the heart, we fixed and stored the heart in $4 \%$ paraformaldehyde in PBS, $\mathrm{pH}=7.4$, until it was embedded in paraffin. Transverse sections ( $4 \mu \mathrm{m}$ thickness) were then cut and hematoxylin and eosin (H\&E)-stained slides prepared at $2 \mathrm{~mm}$ intervals throughout the entire heart.

Immunofluorescence staining and confocal microscopy. Procedures similar to those described in our previous publications (Lin et al., 2004, 2008, 2010) were used for immunofluorescent staining. In summary, $7 \mathrm{~d}$ after toxin injection rats were deeply anesthetized with pentobarbital $(50 \mathrm{mg} /$ $\mathrm{kg}$ ) and euthanized by perfusion through the heart with PBS followed by $4 \%$ paraformaldehyde at $4^{\circ} \mathrm{C}$. After euthanasia, brains were removed, postfixed for $2 \mathrm{~h}$, and cryoprotected with $30 \%$ sucrose for $2 \mathrm{~d}$ at $4^{\circ} \mathrm{C}$. Frozen $20 \mu \mathrm{m}$ coronal slices were cut with a cryostat and stored in $30 \%$ sucrose at $-20^{\circ} \mathrm{C}$. For immunofluorescent staining, tissue sections were washed with PBS, blocked with 10\% donkey normal serum (Jackson ImmunoResearch Laboratories), and then incubated with primary antibodies (see Table 1 for sources and dilution of each antibody) in 10\% donkey normal serum at $25^{\circ} \mathrm{C}$ overnight. After thorough washing with $\mathrm{PBS}$, sections were incubated with affinity-purified fluorescent dyeconjugated secondary antibodies (1:200, Jackson ImmunoResearch Laboratories) at $4^{\circ} \mathrm{C}$ overnight. They were then washed, transferred to slides, air-dried, and mounted with Prolong Gold Antifade Reagents (Invitrogen). Multiple-label immunofluorescent staining was performed for those primary antibodies that were raised in different species in brainstem sections to reduce the number of animals needed. In this case, primary antibodies were mixed in incubation medium as described by us previously (Lin and Talman, 2005; Lin et al., 2007, 2008). Appropriate secondary antibody mixtures (DyLight 488 or Rhodamine Red X or DyLight 649 conjugated, all 1:200, Jackson ImmunoResearch Laboratories) were then used. We analyzed stained sections with a Zeiss LSM 710 confocal laser-scanning microscope (Lin et al., 2000,2004; Lin and Talman, 2002). Digital confocal images were obtained and processed with software provided with the Zeiss LSM 710.

Image analysis for immunofluorescence staining. As described in our previous publication (Lin et al., 2012b), we quantified immunoreactivity (IR, in arbitrary units) in the NTS with NIH ImageJ software, a public domain program available from the NIH (http://rsb.info.nih.gov/ij/). These analyses included all IR observed in cells and processes in the NTS and were normalized to account for differences in the size of NTS between samples. We used 2-3 sections from each animal for each type of staining analyzed. The uninjected side of each section served as intratissue and intra-animal control for the injected side. NTS sections within $300 \mu \mathrm{m}$ of the center of the injection site were used (bregma -13.30 to $-13.90 \mathrm{~mm}$ ) for analysis. A two-tailed paired $t$ test was used to determine whether IR in the injected NTS was significantly different from that of the uninjected side. Significance was accepted at $p \leq$ 0.05 .

\section{Results}

\section{Immunofluorescence studies}

Effects on neuronal markers

Both the microinjection of 6-OHDA and the microinjection of anti-DBH-SAP into the NTS led to significantly $(p<0.01)$ reduced TH-IR and DBH-IR $(p<0.01)$ when compared with those of the control side in the same animals (Fig. 1, Table 2). On the other hand, neither microinjection of 6-OHDA nor anti-DBH-SAP produced appreciable changes in NK1R-IR, NMDAR1-IR, or protein gene product 9.5 (PGP9.5)-IR in the injected NTS (Fig. 2, Table 2). In contrast, our previous immunofluorescence studies of SSP-SAP (Lin et al., 2012b) showed that injection of SSPSAP into NTS led to reduced NMDAR1-IR, NK1R-IR, and PGP9.5-IR in the injected side. In addition, Lin et al. (2012b) reported increased, not decreased, TH-IR in the NTS after injection of SSP-SAP. To facilitate comparison between studies, we include these published results in Table 2. Finally, we observed that microinjection of SAP or blank-SAP did not produce noticeable changes in DBH-IR, TH-IR, NK1R-IR, NMDAR1-IR, or PGP9.5-IR in the injected NTS when compared with those of the control side (Table 2).

Effects on the astrocytic marker glial fibrillary acidic protein Microinjection of anti-DBH-SAP $(p<0.01$, Fig. 3$)$, SSP-SAP $(p<0.01)$, SAP $(p<0.05)$, or blank-SAP $(p<0.01)$ into the 


\section{von Bezold-Jarisch cardiopulmonary reflex}
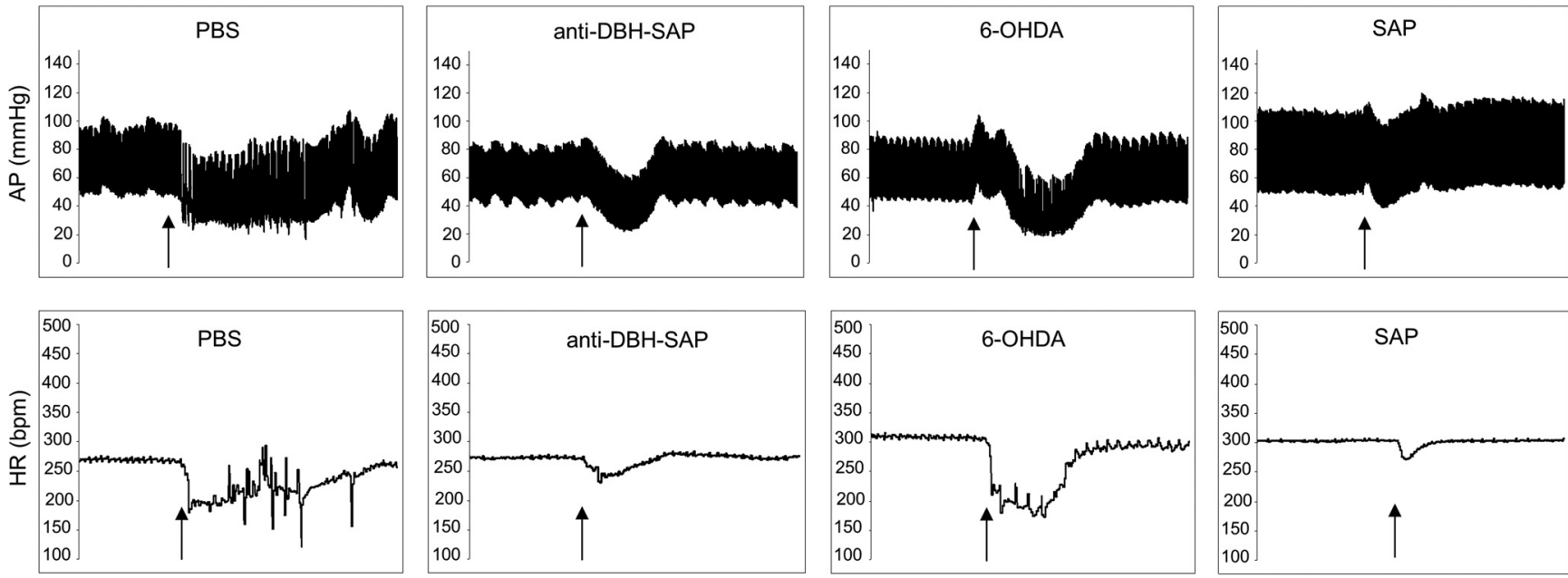

\section{Chemoreflex}
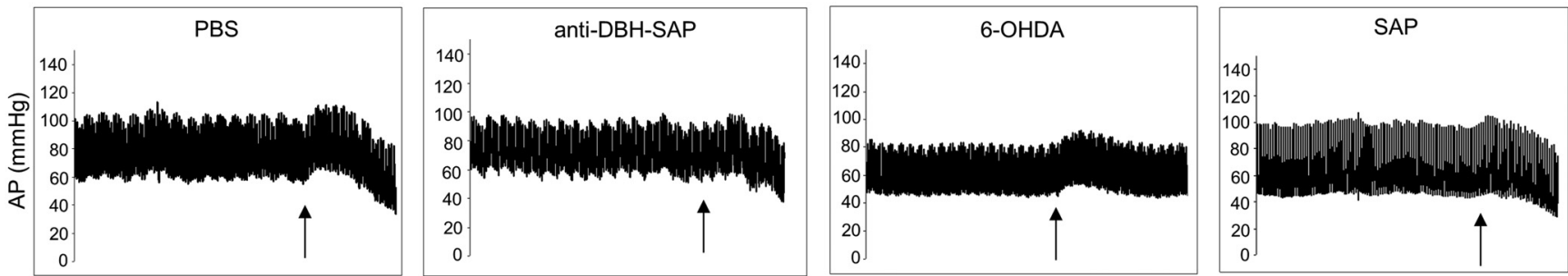

Figure 7. Physiographic recordings show that anti-DBH-SAP and SAP, but not 6-OHDA, reduced AP (top trace) and HR (middle trace) responses to von Bezold-Jarisch reflex, activated by IV infusion of phenylbiguanide, when compared with responses in animals treated with PBS. Similarly, anti-DBH-SAP and SAP, but not 6-OHDA, also reduced AP responses to chemoreflex, activated by IV infusion of $\mathrm{NaCN}$ (bottom trace).

Table 3. Sequence analysis of baroreflexes after injection of PBS and toxins into the NTS

\begin{tabular}{llll}
\hline Injection & Slope & $p$ value (vs PBS) & $p$ value (vs 6-OHDA) \\
\hline PBS $(N=6)$ & $2.29 \pm 0.13$ & Not applicable & Not significant \\
SAP $(N=5)$ & $1.55 \pm 0.24$ & $p<0.05$ & $p<0.05$ \\
SSP-SAP $(N=9)$ & $1.61 \pm 0.13$ & $p<0.01$ & $p<0.05$ \\
Blank-SAP $(N=6)$ & $1.63 \pm 0.16$ & $p<0.01$ & $p<0.05$ \\
Anti-DBH-SAP $(N=7)$ & $1.49 \pm 0.24$ & $p<0.05$ & $p<0.05$ \\
6-OHDA $(N=6)$ & $2.53 \pm 0.36$ & Not significant & Not applicable \\
SAP into area postrema $(N=6)$ & $2.19 \pm 0.23$ & Not significant & Not applicable \\
\hline
\end{tabular}

SAP was also injected into the area postrema as injection outside the NTS control.

Table 4. Summary of cardiovascular and myocardial changes after injection of toxin into the NTS

\begin{tabular}{lccclll}
\hline \multicolumn{7}{c}{ Von } \\
& \multicolumn{7}{c}{ Bezold-Jarisch Coagulation } \\
& \multicolumn{1}{c}{ Baroreflex } & Chemoreflex & Reflex & necrosis & Arrhythmia & AP lability \\
\hline Anti-DBH-SAP & $\downarrow$ & $\downarrow$ & $\downarrow$ & Yes & Yes & Yes \\
SAP & $\downarrow$ & $\downarrow$ & $\downarrow$ & Yes & Yes & Yes \\
Blank-SAP & $\downarrow$ & $\downarrow$ & $\downarrow$ & Yes & Yes & Yes \\
6-OHDA & - & - & - & No & No & No \\
\hline
\end{tabular}

NTS led to a dramatic and significant loss of glial fibrillary acidic protein (GFAP)-IR (Table 2) when compared with that of the control side. In contrast, microinjection of 6-OHDA into the NTS (Fig. 3) led to no appreciable loss of GFAP in the NTS.
Table 5. Barorefex changes after injection of toxin into the NTS

\begin{tabular}{lll}
\hline Injectate & Slope $(\Delta H R / \Delta M A P)$ & $p$ value \\
\hline $\operatorname{PBS}(N=6)$ & $-1.394 \pm 0.15$ & Not significant \\
Anti-DBH-SAP $(N=6)$ & $-0.793 \pm 0.12$ & $p<0.01$ vs PBS \\
$6-0 H D A(N=6)$ & $-1.000 \pm 0.13$ & Not significant \\
SAP $(N=7)$ & $-0.262 \pm 0.06$ & $p<0.01$ vs PBS; $p<0.001$ vs 6-0HDA \\
& & $p<0.05$ vs anti-DBH-SAP
\end{tabular}

Table 6. Von Bezold-Jarisch reflex changes after injection of toxin into the NTS

\begin{tabular}{lllll}
\hline Injectate & $\Delta$ MAP $(\mathrm{mmHg})$ & $p$ value & $\Delta$ HR $(\mathrm{bpm})$ & $p$ value \\
\hline PBS $(N=6)$ & $-27.80 \pm 7.36$ & Not significant & $-100.67 \pm 38.09$ & Not significant \\
Anti-DBH-SAP & $-16.19 \pm 2.20$ & Not significant & $-39.82 \pm 11.88$ & Not significant \\
$\quad(N=6)$ & & & & \\
$6-\mathrm{OHDA}(N=6)$ & $-17.85 \pm 6.20$ & Not significant & $-61.08 \pm 30.33$ & Not significant \\
SAP $(N=7)$ & $-8.82 \pm 2.58$ & $p<0.05$ vs PBS & $-17.81 \pm 3.08$ & $p<0.05$ vs PBS \\
\hline
\end{tabular}

Table 7. Chemoreflex changes after injection of toxin into the NTS

\begin{tabular}{lll}
\hline Injectate & $\Delta$ MAP $(\mathrm{mmHg})$ & $p$ value \\
\hline PBS $(N=6)$ & $8.63 \pm 1.38$ & Not significant \\
Anti-DBH-SAP $(N=6)$ & $6.38 \pm 0.74$ & Not significant \\
$6-0 H D A(N=6)$ & $7.30 \pm 1.41$ & Not significant \\
SAP $(N=7)$ & $4.53 \pm 0.75$ & $p<0.05$ vs PBS \\
\hline
\end{tabular}


Lability of arterial pressure

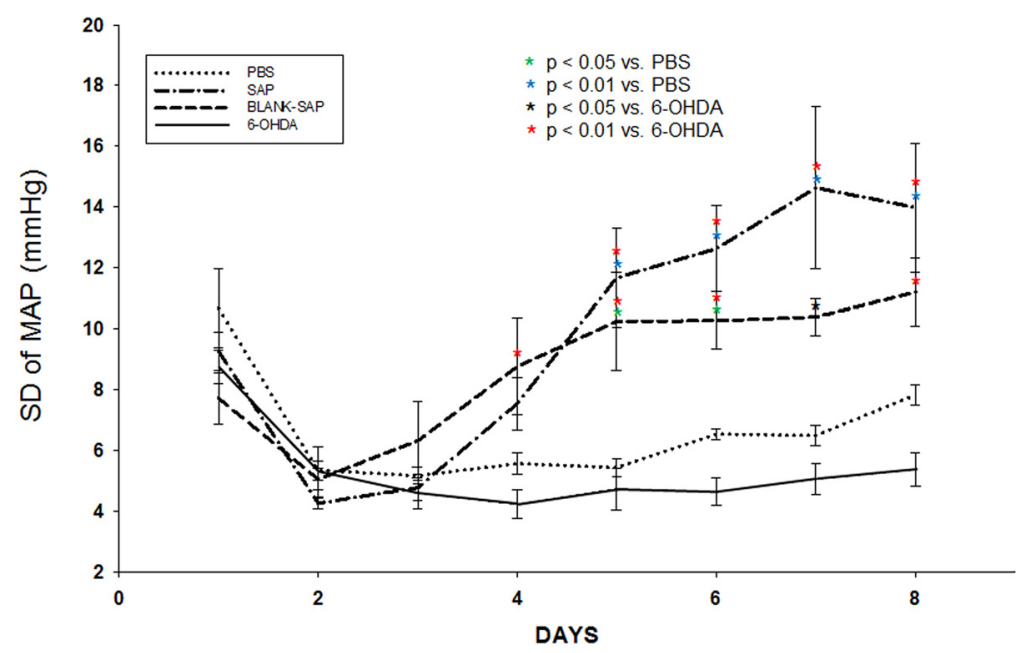

Figure 8. Lability of arterial pressure expressed as the SD of MAP began to appear $4 \mathrm{~d}$ after surgery in animals treated with SAP and blank-SAP when compared with animals treated with $\mathrm{PBS}$ or $6-\mathrm{OHDA}$ and remained significantly different from the latter two groups for the remaining days of the analysis.
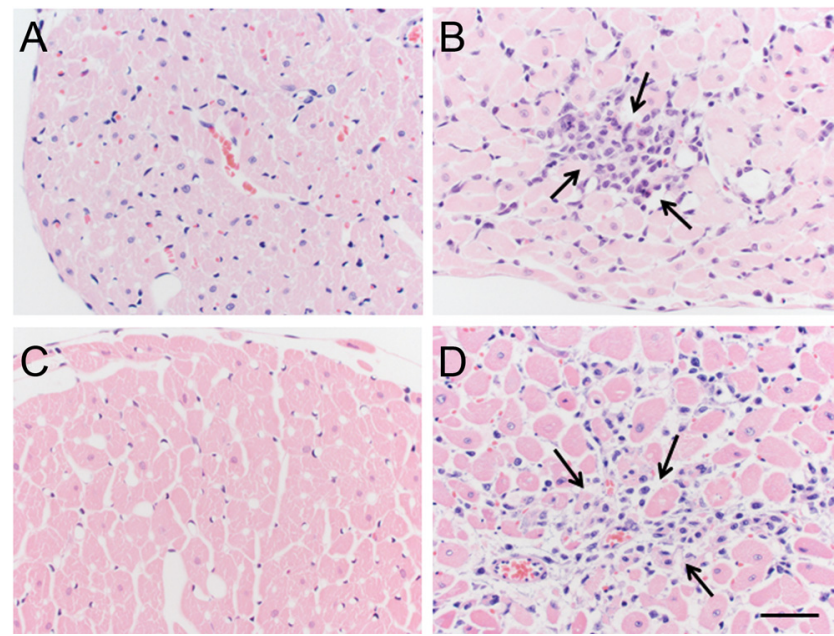

Figure 9. Representative H\&E-stained sections showing basophilic areas that are indicative of resolving microinfarcts (arrows) in myocardium of rats injected with blank-SAP $(\boldsymbol{B})$ or SAP (D). Hearts were evaluated $7 \mathrm{~d}$ following injections. No infarcts were observed in myocardium of rats injected with PBS (A) or 6-OHDA (C). Scale bar, $100 \mu \mathrm{m}$.

The effect of SAP conjugates on GFAP-IR did not appear to be restricted to the NTS. A decrease in GFAP-IR also was seen in the adjacent areas such as the nucleus gracilus and dorsal motor nucleus of vagus (Fig. 3).

\section{Effects on the gap junction protein connexin 43}

By comparing the injected side with the control side we found that there was a significant decrease in gap junction protein connexin 43 (CX43)-IR in the NTS after injection of anti-DBH-SAP $(p<0.01)$, SSP-SAP $(p<0.01$, Fig. 4$)$, SAP $(p<0.01)$, or blank-SAP $(p<0.01)$. We observed only a slight reduction in CX43-IR in the NTS after 6-OHDA injection (Fig. 4, Table 2).

Effects on immunoreactivity for the microglial marker OX42

OX42-IR increased significantly when compared with the control side after 6-OHDA ( $p<0.05$, Fig. 5), anti-DHB-SAP $(p<0.01)$,
SSP-SAP $(p<0.01)$, SAP $(p<0.01$, Fig. $5)$, or blank-SAP $(p<0.01)$ had been injected into the NTS (Table 2).

\section{Cardiovascular reflex effects}

We tested effects of bilaterally injecting PBS, anti-DBH-SAP, 6-OHDA, and SAP on responses to pharmacological activation of the baroreflex, chemoreflex, and von Bezold-Jarisch reflex. We have previously reported effects on the baroreflex, assessed pharmacologically in anesthetized animals, after ablating NTS NK1 neurons by use of SSP-SAP and did not repeat that study here. Anti-DBH-SAP significantly reduced baroreflex responses while SAP significantly reduced all cardiovascular reflex responses (Figs. 6, 7, Tables $3,4,5,6,7)$. In contrast, bilateral injection of 6-OHDA did not significantly affect any of the cardiovascular reflexes (Figs. 6, 7 , Tables 3, 4, 5, 6, 7). Sequence analysis of the baroreflex was performed on rats after bilateral injections into the NTS of PBS, 6-OHDA, SAP, SSP-SAP, blank SAP, or anti-DBH-SAP or after injection into the area postrema of SAP. We had previously reported sequence analysis after anti-DBH-SAP (Talman et al., 2012) but repeated that analysis here for comparison with effects produced by the other injectates. SAP, SSP-SAP, blank-SAP, and anti-DBH-SAP injected bilaterally into NTS significantly reduced baroreflex gain with respect to PBS, but 6-OHDA did not affect that gain. SAP injected into the area postrema (data not shown) did not affect baroreflex gain (Table 3 ).

\section{Lability of arterial pressure}

As has been reported in animals with loss of baroreflex responses from either central or peripheral lesions (Cowley et al., 1973; Talman et al., 1980b; Buchholz et al., 1986), attenuation of baroreflex responses in this study was also accompanied by significant lability of AP. Using lability following bilateral injection of PBS $(N=6)$ into the NTS as the control we found that significant lability, expressed as the SD of MAP, developed in animals treated with bilateral NTS injections of SAP $(N=6)$ on day $5,6,7$, and 8 after the injection or blank-SAP $(N=7)$ on day 5 and 6 after the injection (Fig. 8, Table 4). Of note, we have previously reported loss of baroreflex responses and lability of AP after injection of SSP-SAP and anti-DBH-SAP (Nayate et al., 2009; Talman et al., 2012). Lability of AP was not present after treatment with 6 -OHDA $(N=6)$ on any day when compared with treatment with PBS (Fig. 8). Lability after treatment with 6OHDA was significantly different than after treatment with SAP on day $5,6,7$, and 8 and from treatment with blank-SAP on day $4,5,6,7$, and 8 (Fig. 8).

\section{Cardiac myocytolysis}

Animals treated with SAP and blank-SAP, but not those treated with 6-OHDA, demonstrated multifocal sites of microscopic damage in the cardiac ventricular myocardium (Fig. 9) as we have previously reported after treatment with SSP-SAP and antiDBH-SAP (Nayate et al., 2009; Talman et al., 2012).

\section{Cardiac arrhythmias}

Animals treated with SAP and blank-SAP also demonstrated an increased incidence of ventricular ectopic beats and occasional 
runs of ventricular ectopic beats when compared with control animals (Fig. 10), again as we had previously reported when SAP conjugates had been injected (Nayate et al., 2009; Talman et al., 2012). Such ventricular irritability was not seen in animals treated with 6-OHDA (data not shown). As we have reported in animals treated with SSP-SAP or anti-DBH-SAP (Nayate et al., 2009; Talman et al., 2012), some animals treated with SAP ( 1 of 6 animals) and blank-SAP (1 of 7 animals) died suddenly. In those animals death was preceded by terminal bradycardia followed by asystole (Fig. 11). Bradycardia, asystole, and sudden death were never seen in animals treated with NTS injections of 6-OHDA or PBS or in animals treated with SAP injected into the area postrema immediately adjacent to the NTS.

\section{Discussion}

This study shows that unconjugated SAP preferentially targets astrocytic glia while leaving neurons minimally, if at all, damaged. Damage is indicated by reduction of markers for each cell type. Astrocytic glia were identified by their immunostaining for GFAP (Eng, 1985) and neurons were identified in general by their staining for PGP9.5 (Doran et al., 1983) and specifically by their staining for receptors for select transmitters or for biosynthetic enzymes for the transmitters. This study shows that lesions of glia in the NTS attenuate baroreflex, chemoreflex, and von BezoldJarisch reflex activity and that the degree of reflex attenuation was comparable to that seen with lesions that target both neurons and glia. Thus, it suggests that GFAP-positive astrocytes are necessary for synaptic transmission of cardiovascular reflex signals in the NTS. Finally, changes in cardiovascular reflex control do not correlate with infiltration of the affected area by microglia in that migration of those cells into the NTS was seen after injections of each of the toxins including 6-OHDA, which had no effect on cardiovascular reflexes, lability, or the cardiac consequences associated with interrupted reflex function.

Finding that SAP attenuates cardiovascular reflexes contradicts another study (Abdala et al., 2006) in which saporin was used as a control but produced neither cellular damage in the NTS nor changes in cardiovascular control. However, that study evaluated only NK1R immunoreactivity to indicate SAP toxicity and did not examine effects on GFAP. To our knowledge effects of SAP on GFAP-labeled cells have not previously been reported with SAP injections directly into the CNS parenchyma. When SAP was injected into the CSF but outside the CNS (Hayashida et al., 2012), it tended to enhance labeling for reactive astrocytes in adjacent tissue. In the current study (Fig. 3) we also saw enhanced GFAP labeling adjacent to the injection site, but it is unlikely that the reaction peripheral to the lesion explained the physiologic responses in that the reaction lay in regions that are less capable of producing cardiovascular responses than would be the sites of the lesions themselves (Talman et al., 1980a). It is unclear why the study by Abdala et al. (2006), who injected similar doses of SAP to those used in the current study, did not find cardiovascular changes as a result of the toxin. It is possible that subtle differences in location of the injectate could account for the differ-
Ventricular Ectopic Beat - Saporin
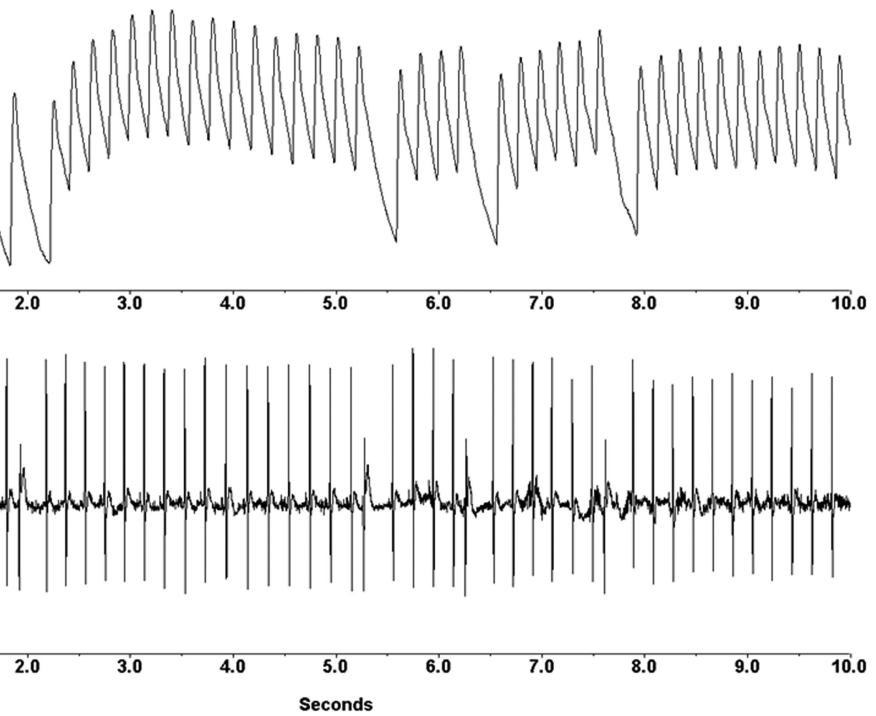

Seconds

Figure 10. Representative ECG (top trace) demonstration of ventricular ectopic beats and associated declines in AP (bottom trace) seen in animals treated with SAP as we have also previously shown in animals treated with anti-DBH-SAP and SSP-SAP (Nayate et al., 2008; Talman et al., 2012). Treatment with 6-0HDA did not lead to such ventricular irritability (data not shown).

ences, but that explanation could only be tested had there been clear indication of the location of injections in their study. Location of injections of toxin without histological confirmation of toxic damage makes comparisons of localization impossible.

Our results showed a dramatic decrease in CX43-IR in the NTS following injection of SAP or SAP-conjugates. CX43 is predominantly found in astrocytes in the brain (Contreras et al., 2004). Therefore, decreased CX43 in the NTS after SAP or SAPconjugate injection is consistent with our observation that astrocytes in the NTS were killed after such injection. Although its role in the NTS is unknown, CX43 plays an important role in the blood-brain barrier (Ezan et al., 2012) and in neurotransmission in the hippocampus (Rouach et al., 2008).

As would be expected (Pekny and Nilsson, 2005), increased numbers of microglia were found in the treated NTS. However, influx of microglia was not only seen with injection of SAPcontaining toxins that were associated with cardiovascular changes but also with introduction into the NTS of 6-OHDA that produced no change in reflex function, myocardial function, or viability. There was, therefore, no correlation between cardiovascular changes in this study and microglial influx while there was correlation between cardiovascular changes and loss of GFAPlabeled glia in the NTS. That observation does not exclude a role for reactive astrocytes in alterations of $\mathrm{AP}$ as has been suggested by others (Waki et al., 2013) who found that excessive amounts of arachidonic acid-leukotriene B4, whose receptors were found exclusively on glia, were associated with elevated AP in spontaneously hypertensive rats. Conversely, spontaneously hypertensive rats treated with arundic acid, which inhibits activation of astrocytes, had lower APs when compared with untreated SHRs (Higashino et al., 2009). Although the current study provides evidence that infiltration of NTS by microglia does not account for cardiovascular effects, it does not exclude the possibility that microglia play a critical role in cardiovascular function when microglia are in the presence of GFAP-positive astrocytes.

Our studies localize effects of SAP conjugates and SAP alone to the NTS and fail to show cardiovascular reflex changes or 

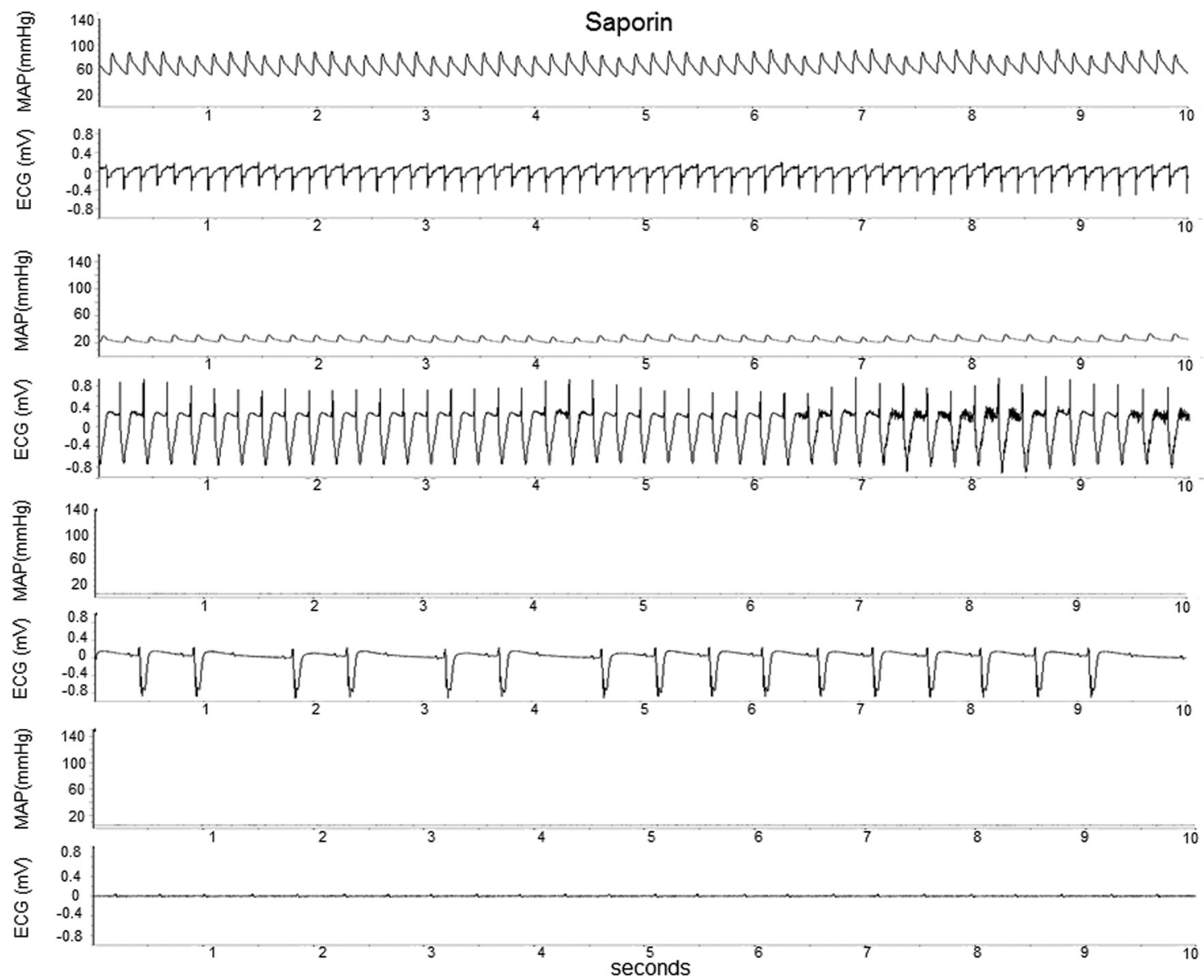

Figure 11. Representative MAP (top trace of each pair) and ECG (second trace of each pair) recordings from an animal that sustained sudden death 1 week after treatment with SAP. Sudden death was associated with asystole that followed bradycardia as we have previously shown in animals treated with SSP-SAP and anti-DBH-SAP (Nayate et al., 2008). No animal treated with 6-OHDA had sudden death or these MAP/ECG changes (data not shown).

changes in cardiovascular control when injections were made into adjacent tissue. In that area postrema injections would enter an area without a blood-brain barrier; failure of those injections to produce cardiovascular responses, like those seen with injection into the NTS, also militates against diffusion of toxin from the site of injection into the circulation to produce effects. In previous studies (Nayate et al., 2009), we microinjected toxin into multiple adjacent sites in the brainstem and saw no cardiovascular changes unless injections affected the NTS itself.

Within each injected site, including the area postrema, injections of SAP or SAP conjugates led to loss of GFAP-labeled astrocytes. To our knowledge this is the first study showing a critical role for glia in cardiovascular reflex transmission through the region, although other studies have suggested that glia may play a critical chemosensory role in ventilatory control (Gourine et al., 2010). Still others have shown that astrocytes respond to vagal afferent stimulation through activation of glutamate receptors on their cell surface (McDougal et al., 2011), and others have implicated glia in responses to hydrogen ion and glial/neuronal interactions in chemoreflex pathways (Gourine and Kasparov, 2011). Those positive studies and our own, suggesting a critical role of glia in neuronal transmission, have now been challenged by a study that found no alteration in autonomic control after putative interference with glial function in NTS (Costa et al., 2013). Again, however, interpretation of the results must be cautious in that disordered glial function was assumed but not tested.
We readily acknowledge that our suggestion that SAP may modulate of neuronal transmission requires direct analysis of neuron-to-neuron transmission in the presence and absence of putative glial modulation, but the current study does support that possibility. We also acknowledge that other studies are needed to exclude any direct effect of SAP on neurons. Clearly, there could be unseen effects; but the current study does support a glial effect on cardiovascular reflex transmission in that glial damage correlates with reflex changes while recognizable effects on neurons in the absence of effects on glia, as occurred with 6-OHDA, is less associated with reflex changes than when recognizable effects were concentrated in glia. These cautionary notes notwithstanding, this study clearly indicates that care must be used in interpreting results of studies using SAP conjugates to "selectively" kill particular neurons, in that, along with loss of specific neurons, there may also be loss of astrocytes in the same region.

SAP belongs to a class of monomeric plant seed ribosomeinactivating proteins (Barbieri et al., 1993). Because it lacks a membrane-binding subunit, it cannot enter cells by receptormediated endocytosis unless it is complexed to a carrier molecule (Ippoliti et al., 2000). However, free SAP has been shown to be internalized in some cells expressing very low-density lipoproteinrelated receptor proteins (Cavallaro et al., 1995). On the other hand, a discrepancy was reported between the level of very lowdensity lipoprotein-related receptor proteins and SAP toxicity 
in some cell lines. Thus, SAP may enter cells via receptorindependent endocytosis (Bagga et al., 2003). Currently, we do not know whether astrocytes in the NTS contain very low-density lipoprotein-related receptor proteins and whether these proteins play a role in SAP toxicity in astrocytes in the NTS. Another possible route through which SAP may enter cells is via the mannose receptor, a very important conduit for cellular uptake and one that may mediate internalization of bacteria, yeast, and ricin (Ezekowitz et al., 1990; Magnússon and Berg, 1993). Expression of the mannose receptor has been demonstrated in cultured murine astrocytes and human brain astrocytes (Burudi et al., 1999; Liu et al., 2004). Further studies are needed to determine whether NTS astrocytes contain mannose receptors and whether mannose receptors are necessary for SAP toxicity in NTS astrocytes.

In summary, this study is the first to show apparently selective glial toxicity by the ribosomal toxin SAP delivered into the NTS. Glial damage, with no discernible neuronal damage, interfered with cardiovascular reflex transmission through the NTS. This study is important both for its physiological implications as well as for its demonstrated ability to damage glia while sparing neurons. The latter suggests potential therapeutic uses of the SAP as has been suggested by others who showed that SAP can target glioma cells (Cimini et al., 2012).

\section{References}

Abdala AP, Schoorlemmer GH, Colombari E (2006) Ablation of NK1 receptor bearing neurons in the nucleus of the solitary tract blunts cardiovascular reflexes in awake rats. Brain Res 1119:165-173. CrossRef Medline

Bagga S, Hosur MV, Batra JK (2003) Cytotoxicity of ribosome-inactivating protein saporin is not mediated through alpha2-macroglobulin receptor. FEBS Lett 541:16-20. CrossRef Medline

Barbieri L, Battelli MG, Stirpe F (1993) Ribosome-inactivating proteins from plants. Biochim Biophys Acta 1154:237-282. CrossRef Medline

Bertinieri G, di Rienzo M, Cavallazzi A, Ferrari AU, Pedotti A, Mancia G (1985) A new approach to analysis of the arterial baroreflex. J Hypertens [Suppl] 3:S79-S81. Medline

Buchholz RA, Hubbard JW, Nathan MA (1986) Comparison of 1-hour and 24-hour blood pressure recordings in central or peripheral baroreceptordenervated rats. Hypertension 8:1154-1163. CrossRef Medline

Burudi EM, Riese S, Stahl PD, Régnier-Vigouroux A (1999) Identification and functional characterization of the mannose receptor in astrocytes. Glia 25:44-55. CrossRef Medline

Cavallaro U, Nykjaer A, Nielsen M, Soria MR (1995) Alpha 2-macroglobulin receptor mediates binding and cytotoxicity of plant ribosome-inactivating proteins. Eur J Biochem 232:165-171. CrossRef Medline

Cimini A, Mei S, Benedetti E, Laurenti G, Koutris I, Cinque B, Cifone MG, Galzio R, Pitari G, Di Leandro L, Giansanti F, Lombardi A, Fabbrini MS, Ippoliti R (2012) Distinct cellular responses induced by saporin and a transferrin-saporin conjugate in two different human glioblastoma cell lines. J Cell Physiol 227:939-951. CrossRef Medline

Contreras JE, Sánchez HA, Véliz LP, Bukauskas FF, Bennett MV, Sáez JC (2004) Role of connexin-based gap junction channels and hemichannels in ischemia-induced cell death in nervous tissue. Brain Res Brain Res Rev 47:290-303. CrossRef Medline

Costa KM, Moraes DJ, Machado BH (2013) Acute inhibition of glial cells in the NTS does not affect respiratory and sympathetic activities in rats exposed to chronic intermittent hypoxia. Brain Res 1496:36-48. CrossRef Medline

Cowley AW Jr, Liard JF, Guyton AC (1973) Role of the baroreceptor reflex in daily control of arterial blood pressure and other variables in dogs. Circ Res 32:564-576. CrossRef Medline

Doran JF, Jackson P, Kynoch PA, Thompson RJ (1983) Isolation of PGP 9.5, a new human neurone-specific protein detected by high-resolution twodimensional electrophoresis. J Neurochem 40:1542-1547. CrossRef Medline

Eng LF (1985) Glial fibrillary acidic protein (GFAP): the major protein of glial intermediate filaments in differentiated astrocytes. J Neuroimmunol 8:203-214. CrossRef Medline

Ezan P, André P, Cisternino S, Saubaméa B, Boulay AC, Doutremer S,
Thomas MA, Quenech'du N, Giaume C, Cohen-Salmon M (2012) Deletion of astroglial connexins weakens the blood-brainbarrier. J Cereb Blood Flow Metab 32:1457-1467. CrossRef Medline

Ezekowitz RA, Sastry K, Bailly P, Warner A (1990) Molecular characterization of the human macrophage mannose receptor: demonstration of multiple carbohydrate recognition-like domains and phagocytosis of yeasts in Cos-1 cells. J Exp Med 172:1785-1794. CrossRef Medline

Gillis RA, Helke CJ, Hamilton BL, Norman WP, Jacobowitz DM (1980) Evidence that substance $\mathrm{P}$ is a neurotransmitter of baro- and chemoreceptor afferents in nucleus tractus solitarius. Brain Res 181:476-481. CrossRef Medline

Gourine AV, Kasparov S (2011) Astrocytes as brain interoceptors. Exp Physiol 96:411-416. Medline

Gourine AV, Kasymov V, Marina N, Tang F, Figueiredo MF, Lane S, Teschemacher AG, Spyer KM, Deisseroth K, Kasparov S (2010) Astrocytes control breathing through $\mathrm{pH}$-dependent release of ATP. Science 329:571-575. CrossRef Medline

Hayashida K, Peters CM, Gutierrez S, Eisenach JC (2012) Depletion of endogenous noradrenaline does not prevent spinal cord plasticity following peripheral nerve injury. J Pain 13:49-57. CrossRef Medline

Head GA, McCarty R (1987) Vagal and sympathetic components of the heart rate range and gain of the baroreceptor-heart rate reflex in conscious rats. J Auton Nerv Syst 21:203-213. CrossRef Medline

Helke CJ, O'Donohue TL, Jacobowitz DM (1980) Substance P as a baroand chemoreceptor afferent neurotransmitter: immunocytochemical and neurochemical evidence in the rat. Peptides 1:1-9. CrossRef Medline

Higashino H, Niwa A, Satou T, Ohta Y, Hashimoto S, Tabuchi M, Ooshima K (2009) Immunohistochemical analysis of brain lesions using S100B and glial fibrillary acidic protein antibodies in arundic acid- (ONO-2506) treated stroke-prone spontaneously hypertensive rats. J Neural Transm 116:1209-1219. CrossRef Medline

Ippoliti R, Lendaro E, Benedetti PA, Torrisi MR, Belleudi F, Carpani D, Soria MR, Fabbrini MS (2000) Endocytosis of a chimera between human prourokinase and the plant toxin saporin: an unusual internalization mechanism. FASEB J 14:1335-1344. CrossRef Medline

Itoh H, Buñag RD (1993) Age-related reduction of reflex bradycardia in conscious rats by catecholaminergic nucleus tractus solitarius lesions. Mech Ageing Dev 67:47-63. CrossRef Medline

Itoh H, Alper RH, Buñag RD (1992) Baroreflex changes produced by serotonergic or catecholaminergic lesions in the rat nucleus tractus solitarius. J Pharmacol Exp Ther 261:225-233. Medline

Lin LH, Talman WT (2002) Coexistence of NMDA and AMPA receptor subunits with nNOS in the nucleus tractus solitarii of rat. J Chem Neuroanat 24:287-296. CrossRef Medline

Lin LH, Talman WT (2005) Nitroxidergic neurons in rat nucleus tractus solitarii express vesicular glutamate transporter 3. J Chem Neuroanat 29:179-191. CrossRef Medline

Lin LH, Emson PC, Talman WT (2000) Apposition of neuronal elements containing nitric oxide synthase and glutamate in the nucleus tractus solitarii of rat: a confocal microscopic analysis. Neurosci 96:341-350. CrossRef

Lin LH, Edwards RH, Fremeau RT, Fujiyama F, Kaneko T, Talman WT (2004) Vesicular glutamate transporter colocalizes with neuronal nitric oxide synthase in rat nucleus tractus solitarii. Neuroscience 123:247-255. CrossRef Medline

Lin LH, Taktakishvili O, Talman WT (2007) Identification and localization of cell types that express endothelial and neuronal nitric oxide synthase in the rat nucleus tractus solitarii. Brain Res 1171:42-51. CrossRef Medline

Lin LH, Taktakishvili OM, Talman WT (2008) Colocalization of neurokinin-1, $\mathrm{N}$-methyl-D-aspartate, and AMPA receptors on neurons of the rat nucleus tractus solitarii. Neuroscience 154:690-700. CrossRef Medline

Lin LH, Langasek JE, Talman LS, Taktakishvili OM, Talman WT (2010) Feline immunodeficiency virus as a gene transfer vector in the rat nucleus tractus solitarii. Cell Mol Neurobiol 30:339-346. CrossRef Medline

Lin LH, Nitschke Dragon D, Jin J, Tian X, Chu Y, Sigmund C, Talman WT (2012a) Decreased expression of neuronal nitric oxide synthase in the nucleus tractus solitarii inhibits sympathetically mediated baroreflex responses in rat. J Physiol 590:3545-3559. CrossRef Medline

Lin LH, Nitschke Dragon D, Talman WT (2012b) Collateral damage and compensatory changes after injection of a toxin targeting neurons with the neurokinin-1 receptor in the nucleus tractus solitarii of rat. J Chem Neuroanat 43:141-148. CrossRef Medline 
Liu Y, Liu H, Kim BO, Gattone VH, Li J, Nath A, Blum J, He JJ (2004) CD4-independent infection of astrocytes by human immunodeficiency virus type 1: requirement for the human mannose receptor. J Virol 78: 4120-4133. CrossRef Medline

Madden CJ, Ito S, Rinaman L, Wiley RG, Sved AF (1999) Lesions of the C1 catecholaminergic neurons of the ventrolateral medulla in rats using antiDbetaH-saporin. Am J Physiol 277:R1063-R1075. Medline

Magnússon S, Berg T (1993) Endocytosis of ricin by rat liver cells in vivo and in vitro is mainly mediated by mannose receptors on sinusoidal endothelial cells. Biochem J 291:749-755. Medline

Matsumoto S, Mokashi A, Lahiri S (1987) Cervical preganglionic sympathetic nerve activity and chemoreflexes in the cat. J Appl Physiol 62:17131720. CrossRef Medline

McDougal DH, Hermann GE, Rogers RC (2011) Vagal afferent stimulation activates astrocytes in the nucleus of the solitary tract via AMPA receptors: evidence of an atypical neural-glial interaction in the brainstem. J Neurosci 31:14037-14045. CrossRef Medline

Minisi AJ, Dibner-Dunlap M, Thames MD (1989) Vagal cardiopulmonary baroreflex activation during phenylephrine infusion. Am J Physiol 257: R1147-R1153. Medline

Nathan MA, Reis DJ (1977) Chronic labile hypertension produced by lesions of the nucleus tractus solitarii in the cat. Circ Res 40:72-81. CrossRef Medline

Nattie EE, Li A, Richerson GB, Lappi DA (2004) Medullary serotonergic neurones and adjacent neurones that express neurokinin-1 receptors are both involved in chemoreception in vivo. J Physiol 556:235-253. CrossRef Medline

Nayate A, Moore SA, Weiss R, Taktakishvili OM, Lin LH, Talman WT (2009) Cardiac damage after lesions of the nucleus tractus solitarii. Am J Physiol Regul Integr Comp Physiol 296:R272-R279. CrossRef Medline

Pekny M, Nilsson M (2005) Astrocyte activation and reactive gliosis. Glia 50:427-434. CrossRef Medline

Riley J, Lin LH, Chianca DA Jr, Talman WT (2002) Ablation of NK1 receptors in rat nucleus tractus solitarii blocks baroreflexes. Hypertension 40: 823-826. CrossRef Medline

Rouach N, Koulakoff A, Abudara V, Willecke K, Giaume C (2008) Astroglial metabolic networks sustain hippocampal synaptic transmission. Science 322:1551-1555. CrossRef Medline

Sévoz C, Callera JC, Machado BH, Hamon M, Laguzzi R (1997) Role of serotonin $_{3}$ receptors in the nucleus tractus solitarii on the carotid chemoreflex. Am J Physiol 272:H1250-H1259. Medline
Snyder DW, Nathan MA, Reis DJ (1978) Chronic lability of arterial pressure produced by selective destruction of the catecholamine innervation of the nucleus tractus solitarii in the rat. Circ Res 43:662-671. CrossRef Medline

Sparapani M, Buonamici L, Ciani E, Battelli MG, Ceccarelli G, Stirpe F, Contestabile A (1997) Toxicity of ricin and volkensin, two ribosomeinactivating proteins, to microglia, astrocyte, and neuron cultures. Glia 20:203-209. CrossRef Medline

Stauss HM, Moffitt JA, Chapleau MW, Abboud FM and Johnson AK (2006) Baroreceptor reflex sensitivity estimated by the sequence technique is reliable in rats. Am J Physiol Heart Circ Physiol 291:H482-H4823. Medline

Talman WT, Perrone MH, Reis DJ (1980a) Evidence for L-glutamate as the neurotransmitter of baroreceptor afferent nerve fibers. Science 209:813 815. CrossRef Medline

Talman WT, Snyder DW, Reis DJ (1980b) Chronic lability of arterial pressure produced by destruction of A2 catecholaminergic neurons in rat brainstem. Circ Res 46:842-853. CrossRef Medline

Talman WT, Dragon DN, Jones SY, Moore SA, Lin LH (2012) Sudden death and myocardial lesions after damage to catecholamine neurons of the nucleus tractus solitarii in rat. Cell Mol Neurobiol 32:1119-1126. CrossRef Medline

Tsutsui Y, Nishizawa K, Kai N, Kobayashi K (2011) Lever pressing responses under a fixed-ratio schedule of mice with 6-hydroxydopamine-induced dopamine depletion in the nucleus accumbens. Behav Brain Res 217:60 66. CrossRef Medline

Waki H, Hendy EB, Hindmarch CC, Gouraud S, Toward M, Kasparov S, Murphy D, Paton JF (2013) Excessive leukotriene B4 in nucleus tractus solitarii is prohypertensive in spontaneously hypertensive rats. Hypertension 61:194-201. CrossRef Medline

Wiley RG, Kline RH, IV (2000) Neuronal lesioning with axonally transported toxins. J Neurosci Methods 103:73-82. CrossRef Medline

Wiley RG, Lappi DA (1997) Destruction of neurokinin-1 receptor expressing cells in vitro and in vivo using substance P-saporin in rats. Neurosci Lett 230:97-100. CrossRef Medline

Wiley RG, Lappi DA (1999) Targeting neurokinin-1 receptor-expressing neurons with $[\mathrm{Sar} 9, \mathrm{Met}(\mathrm{O} 2) 11$ substance P-saporin. Neurosci Lett 277: 1-4. CrossRef Medline

Wilkinson KA, Fu Z, Powell FL (2011) Ventilatory effects of substance $\mathrm{P}$-saporin lesions in the nucleus tractus solitarii of chronically hypoxic rats. Am J Physiol Regul Integr Comp Physiol 301:R343-R350. CrossRef Medline 